\title{
RESULTS FROM ARTHROSCOPIC REPAIR OF ISOLATED TEARS OF THE SUBSCAPULARIS TENDON
}

\begin{abstract}
Glaydson Gomes Godinho', Flávio de Oliveira França², José Márcio Alves Freita ${ }^{3}$, Flávio Márcio Lago Santos ${ }^{4}$, Ricardo Barreto Monteiro dos Santos ${ }^{5}$, Thiago Martins Taglietti ${ }^{5}$, Carlos Leonidas Escobar Guevara ${ }^{5}$
\end{abstract}

\begin{abstract}
Objective: To evaluate the functional and clinical outcomes and identify prognostic factors in patients undergoing arthroscopic repair of isolated tears of the subscapularis tendon. Methods: Between January 2003 and May 2009, we identified 18 shoulders with isolated tears or deinsertions that were complete or affected at least one third of the subscapularis tendon and underwent arthroscopic repair. Results: Three shoulders (17\%) showed lesions in the upper third of the subscapularis; nine shoulders $(50 \%)$ showed lesions in the upper two thirds; and six shoulders $(33 \%)$ presented complete tears. In comparing the range of lateral rotation of the injured shoulder between before surgery and the time of the reevaluation, there was no statistical difference $(p=0.091)$. The LHBT was damaged in
\end{abstract}

\section{INTRODUCTION}

The tendon of the subscapularis muscle is located in the anterior portion of the rotator cuff. It is the main medial rotator of the humerus and contributes towards the dynamic anterior stability of the glenohumeral joint. It is the most important muscle not only for glenohumeral joint stability but also for function, since it contributes $52 \%$ of the shoulder abduction moment, while the supraspinatus contributes $14 \%$ and the infraspinatus and teres minor contribute $32 \%^{(1,2)}$. Its insertion extends from anteriorly in the lesser tubercle to posteriorly and laterally above the intertubercular sulcus, thus coalescing with the supraspinatus fibers, coracohumeral ligament and superior glenohumeral
11 shoulders (61\%). According to the Constant score validation, we had excellent and good results in $83 \%$ of the cases and $17 \%$ were reasonable. The reevaluations on three patients showed re-tearing on MRI. Acromioplasty was performed on ten patients and this procedure did not represent statistical differences in the final results $(p=0.57)$. Conclusions: There was no statistically significant difference in relation to preoperative lateral rotation between the injured shoulder and the contralateral side. There was no significant loss of lateral rotation after surgery. The LHBT may be normal in deinsertions of the subscapularis tendon. Acromioplasty did not influence the results. The re-tearing rate for arthroscopic repair of the subscapularis tendon was $16.6 \%$.

Keywords - Shoulder; Arthroscopy; Rotator Cuff ligament to form the reflection pulley, which is an important stabilizer of the long head biceps tendon $(\text { LHBT })^{(3,4)}$. Its amplitude is $7.3 \mathrm{~cm}$, and it is the strongest muscle of the rotator cuff ${ }^{(5)}$. The upper two-thirds of the craniocaudal extent of the subscapularis present a tendon insertion, while the lower one-third is inserted directly into the humerus by means of the muscle fibers, with a fine membranous structure ${ }^{(6)}$. In the tendinous portion of the subscapularis, $36 \%$ is intra-articular ${ }^{(7)}$.

Rotator cuff injuries are common sources of shoulder pain and dysfunction ${ }^{(8)}$. Isolated deinsertion of the subscapularis is infrequent. The total incidence of rotator cuff injuries reported in the literature is $4 \%$,

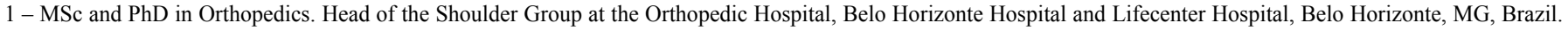

2 - Attending Surgeon in the Shoulder Group at the Orthopedic Hospital and Lifecenter Hospital, Belo Horizonte, MG, Brazil.

3 - Attending Surgeon in the Shoulder Group at the Orthopedic Hospital, Belo Horizonte Hospital and Lifecenter Hospital, Belo Horizonte, MG, Brazil.

4 - Attending Surgeon in the Shoulder Group at the Orthopedic Hospital and Lifecenter Hospital, Belo Horizonte, MG, Brazil.

5 - Resident in the Shoulder Group at the Orthopedic Hospital, Belo Horizonte Hospital and Lifecenter Hospital, Belo Horizonte, MG, Brazil.

Work performed at the Orthopedic Hospital, Belo Horizonte Hospital and Lifecenter Hospital, Belo Horizonte, MG, Brazil.

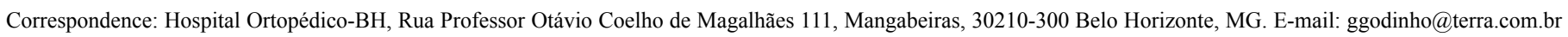
Work received for publication: June 21, 2011; accepted for publication: August 19, 2011.
}

The authors declare that there was no conflict of interest in conducting this work 
and these injuries are most frequent among men in their fifth decade of life ${ }^{(9-11)}$. One of the principal symptoms of a compromised subscapularis is pain that is more localized on the anterior face of the shoulder, in comparison with other rotator cuff tears ${ }^{(8)}$. Associated involvement of the LHBT is observed in $31 \%$ to $56 \%$ of the cases and is generally a source of symptoms ${ }^{(9,11,12)}$. Arthroscopic viewing is the best means of diagnosing subscapularis lesions, since more than $90 \%$ of such lesions start on the joint face and cephalic portion, close to the insertion in the lesser tubercle ${ }^{(13)}$.

Our aim here was to evaluate the functional and clinical results and identify prognostic factors in patients undergoing isolated deinsertion of the subscapular tendon arthroscopically.

\section{MATERIAL AND METHODS}

\section{Description of the sample and inclusion and ex- clusion criteria}

Between January 2003 and May 2009, 2594 shoulders underwent arthroscopic repair of the rotator cuff at the Belo Horizonte Hospital, Lifecenter Hospital and Orthopedic Hospital. We retrospectively identified 18 shoulders $(0.7 \%)$ that underwent arthroscopic repair involving isolated of the subscapularis and fitted within the inclusion and exclusion criteria. Patients whose length of follow-up was less than one year, with partial tears only in the thickness of the subscapular tendon, without complete deinsertion of part or all of the tendon, or any associated lesions in other tendons of the rotator cuff. In addition, patients who underwent subscapularis repair by means of an open procedure, cases of rerupture after the operation and cases of sequelae of infection or advanced osteoarthrosis. The indication for arthroscopic repair was isolated tearing or deinsertion that was complete or affected at least one third of the subscapularis, was of degenerative or traumatic origin and was associated with functional deficit and pain.

Eighteen patients (18 shoulders) were evaluated: 13 men $(72.2 \%)$ and five women $(27.8 \%)$. Their mean age was 59 years (43-76 years). The length of follow-up ranged from 12 to 87 months, with a mean of 34.3 months. The right shoulder was affected in 12 patients and the left in six. The dominant side was affected in 12 cases $(66.7 \%)$.

This study was authorized by the medical ethics committees of the institutions involved. The patients agreed to participate through giving their free and informed consent, as approved by the institutions' ethics committees.

Nine of the patients had suffered traumatic deinsertion: eight through a fall mechanism involving hyperextension with external rotation; and one due to a car accident. In the other nine cases, we did not identify any traumatic event in their clinical histories, and thus these cases were classified as presenting degenerative etiology. The mean time that elapsed between the start of symptoms and the surgical procedure was 5.8 months (1-36 months).

\section{Variables analyzed}

Preoperatively, the patients were evaluated using range of motion (ROM) measurements and by means of sufficiency tests for the subscapularis: the lift-off and belly-press tests. The latter was used only when the patient presented limitations of passive Internal rotation $^{(12)}$. The lift-off test is based on observation of the weakness of Internal rotation, which is most easily demonstrated with the upper arm in hyperextension with Internal rotation, and with the dorsum of the hand positioned at the L3 level, which is when the subscapularis is at its maximum amplitude of contraction. Patients with subscapularis tears are incapable of moving the dorsum of the hand away from the back. Gerber et $a l^{(11)}$ described an alternative maneuver, the belly-press test, for identifying subscapularis tears in situations when the lift-off test could not be performed due to pain or limitation of ROM. In the belly-press test, subscapularis function is tested by asking the patient to press his hand onto his abdomen. If the elbow remains in front of the trunk with the wrist extended, the subscapularis is functional. If the wrist is flexed, thereby compensating for the Internal rotation with the strength of the posterior deltoid, the test will be positive ${ }^{(12)}$. Both tests, when positive, indicate dysfunction of the subscapularis. Before the operation, all the patients underwent magnetic resonance imaging to assess the degree of deinsertion of the subscapular tendon (Figure 1). This was classified based on the magnetic resonance images as follows: complete tear affecting the upper third of its craniocaudal extent; complete tear affecting two thirds of the extent; and total tear (Figures 2 and 3).

The patients were asked to visit the outpatient clinic for evaluations on their range of motion and tests on 

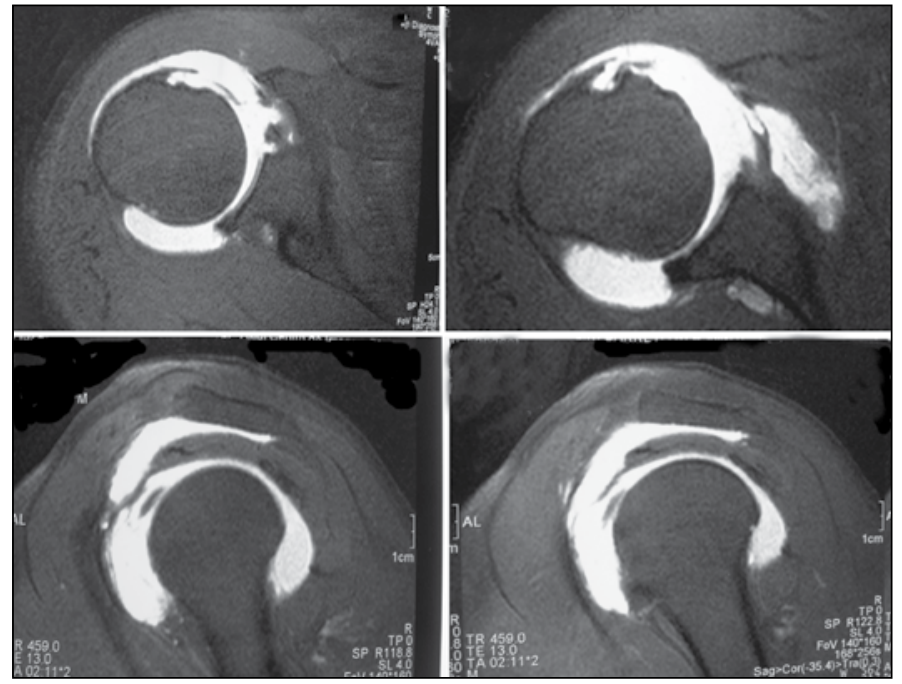

Figure 1 - Magnetic arthro-resonance showing subacromial-subdeltoid bursa filled with paramagnetic contrast, due to complete tearing of the subscapular tendon. The LHBT was seen to be subluxated medially.

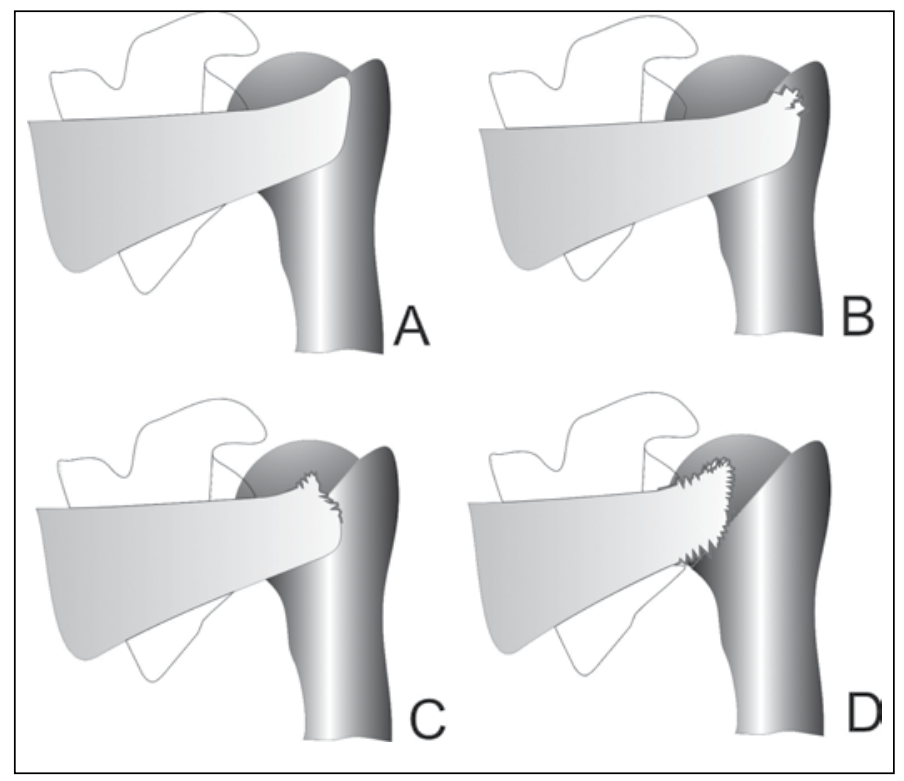

Figure 2 - Representative diagram showing the three types of complete tearing of the subscapular tendon: undamaged $(A)$; affecting the upper third of the craniocaudal extent (B); affecting two thirds of the extent (C); and total (D).

the subscapularis ${ }^{(12)}$, and the results were scored according to the Constant and Murley method ${ }^{(14)}$. The scores thus obtained were grouped into categories according to the methodological criteria described by Boehm: $91-$ 100 points, excellent; 81-90, good; 71-80, satisfactory; $61-70$, adequate; less than 60 points, weak $^{(15)}$.

\section{Surgical technique}

After administration of general anesthesia in association with regional blockade of the brachial plexus, the patients were positioned in lateral decubitus

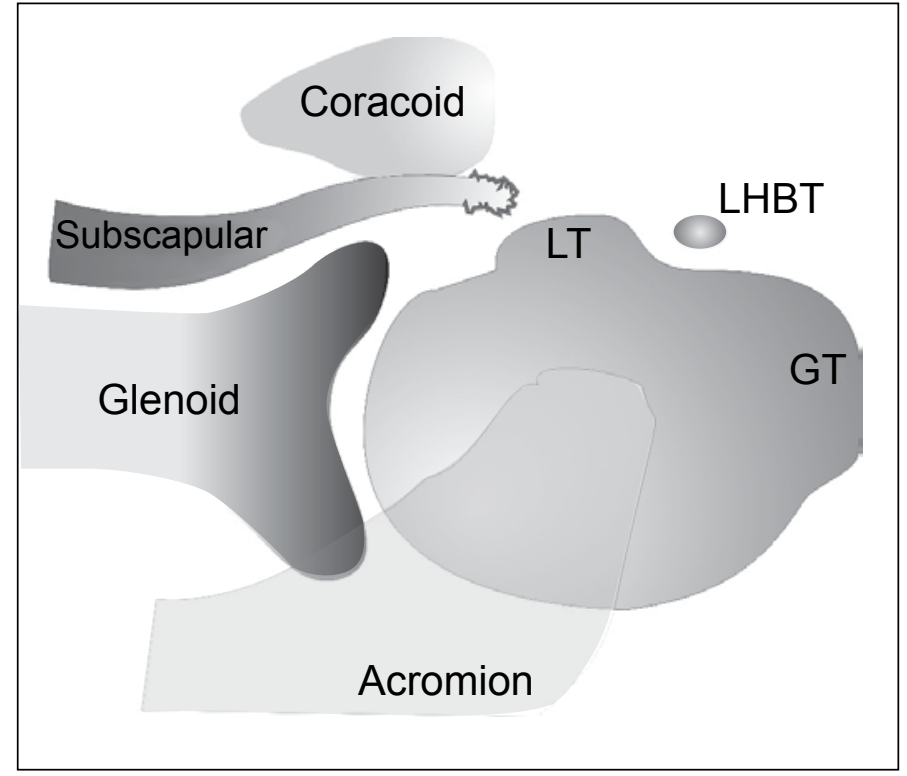

Figure 3 - Schematic drawing in axial view showing complete tearing of the total thickness of the subscapularis tendon. LT: lesser tubercle; GT: greater tubercle; LHBT: long head biceps tendon.

with the arm abducted at 20 to $30^{\circ}$ and flexed at $20^{\circ}$. Arthroscopy was started through the standard posterior portal, using a $30^{\circ}$ optic device, followed by assessment of the joint. In this, the conditions of the LHBT and the subscapularis tendon were assessed. The stability of the LHBT in the intertubercular sulcus was evaluated dynamically, by asking the attending surgeon to perform medial and external rotation on the limb. In situations in which limb instability was observed, tenotomy or tenodesis was then performed. In situations of partial lesions of the biceps, debridement was performed if the lesion affected less than $50 \%$ of the thickness. The anterosuperior portal $(1 \mathrm{~cm}$ anterior to the anterolateral angle of the acromion) was used for debridement, tenotomy or tenodesis of the LHBT, if necessary and subsequently was used to help in suturing the subscapularis. The anteroinferior portal, which was constructed slightly laterally to the lateral edge of the coracoid process, was used for surgical instrumentation.

Acromioplasty was performed when bursal inspection showed the presence of signs of impact on the anteroinferior acromion or subacromial spur.

After the surgery, the patients had to use a Velpeau sling for three weeks if the deinsertion was partial, or for six weeks if it was complete. Following the immobilization period, a physiotherapy protocol for improving the range of motion and for strengthening was started. 


\section{STATISTICAL ANALYSIS}

For descriptive statistical analysis, the mean and the minimum and maximum values were used. For analysis on the continuous variables, the nonparametric Wilcoxon text was used, while the $t$ test was used for independent variables. The significance level was taken to be $\mathrm{p}<0.05$. For the statistical calculations, the resources of the R statistical software (version 2.11.1) were used.

\section{RESULTS}

Three shoulders (17\%) presented deinsertion of the upper third of the subscapularis; nine shoulders $(50 \%)$, the upper two thirds; and six shoulders (33\%), complete deinsertion. In the preoperative evaluation, the mean degree of external rotation of the affected limb was $90^{\circ}$ (range: $60^{\circ}$ to $110^{\circ}$ ), while the mean for the unaffected side was $85^{\circ}$ (range: $60^{\circ}$ to $90^{\circ}$ ), without any statistical difference $(p=0.073)$. Comparison of the amplitude of external rotation of the affected limb between before the operation and the time of the reassessment showed that there was no statistical difference $(p=0.091)$ (Table 1$)$.

To attach the subscapularis to the lesser tubercle, a mean of two anchors was used (range: 0-4 anchors). In one case, the tear in the subscapular tendon occurred in the substance of the tendon, and this was repaired with three side-to-side stitches. Coracoplasty was not done in any of the cases. Tenodesis of the LHBT was performed on three shoulders $(37.5 \%)$ and was included in suturing the subscapularis.

The degree of active anterior elevation before the operation ranged from 90 to $180^{\circ}$, with a mean of $162^{\circ}$, while the range was from 150 to $180^{\circ}$ after the operation, with a mean of $176^{\circ}(\mathrm{p}=0.61)$. In the preoperative evaluation, 17 patients presented a positive lift-off test. There was only a single patient on whom this test could not be done, and this was because of limited Internal rotation (level of the gluteus). The belly-press test on this patient was positive. Three patients who presented positive lift-off tests at the time of the reassessment had magnetic resonance images showing rerupture (Table 2).

During the arthroscopic evaluation, the LHBT was seen to be affected in 11 shoulders $(61 \%$; $95 \%$ confidence interval: 38.6-83.6). In eight cases, the LHBT was found to be dislocated or subluxated; in two cases, it was torn; and in one case, it was stable but more than $50 \%$ of its thickness was compromised. In these cases, tenotomy was performed in six cases and tenodesis in three cases. In the other seven cases, no lesion or instability of the LHBT was observed. Comparison of the Constant and Murley score results between the group in which the LHBT was shown to be compromised and the group in which it was not affected did not show any statistical difference $(\mathrm{p}=0.083)($ Table 3$)$.

Table 1 - Evaluation on the range of motion of lateral rotation.

\begin{tabular}{|c|c|c|}
\hline External rotation & Mean (min-max) & $\mathbf{p}$ \\
\hline $\begin{array}{l}\text { Preoperative external rotation of the } \\
\text { unaffected side }\end{array}$ & $85^{\circ}\left(60^{\circ}-90^{\circ}\right)$ & \multirow{3}{*}{$\begin{array}{l}\} p=0.073^{*} \\
\} p=0.091^{*}\end{array}$} \\
\hline $\begin{array}{l}\text { Preoperative external rotation of the } \\
\text { affected side }\end{array}$ & $90.5^{\circ}\left(60^{\circ}-110^{\circ}\right)$ & \\
\hline $\begin{array}{l}\text { Postoperative external rotation of } \\
\text { the affected side }\end{array}$ & $81.9^{\circ}\left(60^{\circ}-100^{\circ}\right)$ & \\
\hline
\end{tabular}

* Wilcoxon test.

Table 2 - Physical examination on the affected limb, before and after the operation.

\begin{tabular}{l|c|c}
\hline \multicolumn{1}{c|}{ Variables analyzed } & Before operation & After operation \\
\hline \multicolumn{3}{c}{ Range of motion } \\
\hline - Active anterior elevation & $162.7^{\circ}(90-180)$ & $176.1^{\circ}(150-180)$ \\
\hline $\begin{array}{l}\text { - Lateral rotation with the upper } \\
\text { arm adducted }\end{array}$ & $90.5^{\circ}(60-110)$ & $81.9^{\circ}(60-100)$ \\
\hline $\begin{array}{l}\text { - Lateral rotation with the upper } \\
\text { arm abducted at } 90^{\circ}\end{array}$ & $90^{\circ}(80-100)$ & $93.8^{\circ}(80-110)$ \\
\hline - Medial rotation & T12 (T7-L5) & T7 (T7-L5) \\
\hline
\end{tabular}

Tests to evaluate subscapular function

\begin{tabular}{l|c|c}
\hline - Lift-off test $(+)^{*}$ & $n=17(94.4 \%)$ & $n=3(16.6 \%)$ \\
\hline - Belly-press test $(+)^{*}$ & $n=1(5.6 \%)^{\dagger}$ & $n=3(16.6 \%)$ \\
\hline
\end{tabular}

Source: research data.

* Indicates a positive test for functional insufficiency of the subscapularis.

† Patient with limitation of medial rotation on the gluteus; it was not possible to perform the lift-off test. $\ddagger$ Values corresponding to vertebral level.

Table 3 - Arthroscopic evaluation of the LHBT, n (\%).

\begin{tabular}{|c|c|c|}
\hline Inspection/procedure & n (\%) & $p$ \\
\hline Arthroscopic inspection of the LHBT & $n=18$ & \\
\hline LHBT stable and unaffected & $\mathrm{n}=7(39 \%)$ & \multirow{2}{*}{\}$p=0.083^{*}$} \\
\hline LHBT affected & $\begin{array}{c}\mathrm{n}=11(61 \%) \\
\mathrm{IC}(38.6 \text { a } 83.6)^{\dagger}\end{array}$ & \\
\hline - Dislocated or subluxated & $n=8(44 \%)$ & \\
\hline - Tear & $\mathrm{n}=2(11 \%)$ & \\
\hline - Stable, with lesion greater than $50 \%$ & $n=1(6 \%)$ & \\
\hline Procedure performed on the LHBT & $\mathbf{n}=\mathbf{9}$ & \\
\hline - Tenotomy & $n=6(67 \%)$ & \\
\hline - Tenodesis & $\mathrm{n}=3(33 \%)$ & \\
\hline
\end{tabular}


Application of the Constant and Murley score to evaluate the results after the operation showed that the range of scores was from 64.6 to 99 points, with a mean of 85.6 points (Table 4 ).

Using the validation of the Constant score described by Boehm ${ }^{(15)}$, we found that $39 \%$ of the patients had excellent results; $44 \%$, good; and $17 \%$, adequate (Figure 4).

Acromioplasty was performed in 10 cases. All of these cases presented signs of subacromial friction on inspection. Statistically, no influence from this procedure was seen in the results $(p=0.57)$ (Table 5).

Table 4 - Postoperative results assessed by means of the Constant and Murley score.

\begin{tabular}{c|c}
\hline Constant and Murley score & Mean (min-max) \\
\hline - Pain & $12.5(5-15)$ \\
\hline - Activity & $19.7(18-20)$ \\
\hline - Mobility & $37.7(28-40)$ \\
\hline - Strength & $15.5(6.6-26.4)$ \\
\hline Total & $85.6(64.6-99)$ \\
\hline
\end{tabular}

Source: research data.

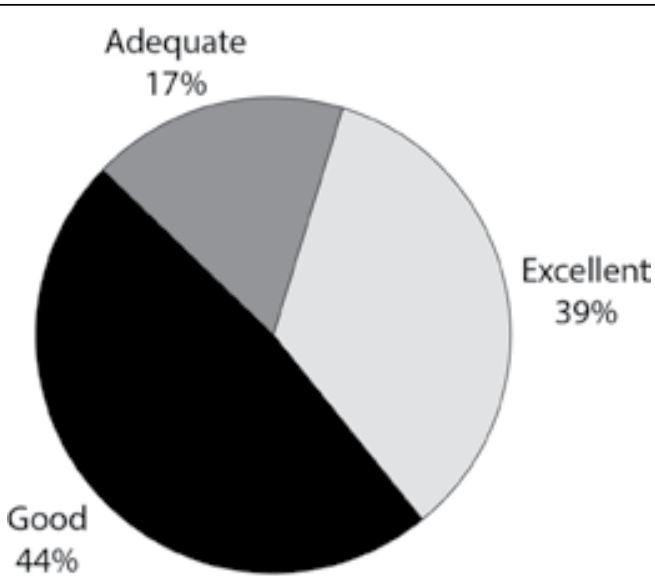

Figure 4 - Results expressed as percentages obtained through Boehm's validation ${ }^{(15)}$.

Table 5 - Evaluation of the scores relating to the Constant variable according to acromioplasty procedure group.

\begin{tabular}{c|c|c|c|c}
\hline $\begin{array}{c}\text { Acromioplasty } \\
\text { procedure }\end{array}$ & Cases & (\%) & $\begin{array}{c}\text { Constant } \\
\text { Mean (min-max) }\end{array}$ & p \\
\hline No & 8 & $45 \%$ & $87.22(64.6-99)$ & \multirow{2}{*}{$0.571^{*}$} \\
\hline Yes & 10 & $55 \%$ & $84.39(73-97)$ & \\
\hline
\end{tabular}

Source: research data.

* $\mathrm{t}$ test for independent variables.

\section{DISCUSSION}

Identification and arthroscopic repair of lesions of the subscapularis has received attention recently. Wright et $a l^{(16)}$ evaluated six shoulders of fresh cadavers arthroscopically, using a 30-degree optic device with viewing through a standard posterior portal.
They observed only $26 \% \pm 11 \%$ of the tendon area and concluded that the arthroscopic viewing was incomplete. Burkhart and Brady ${ }^{(17)}$ recommended that a 70-degree optic device should be used for evaluating the subscapularis.

We did not find any difficulty in identifying the lesions of the subscapularis and performing the repair solely using a 30-degree optic device, by doing this in association with the maneuver of rotating the upper arm medially in order to improve the viewing of the cephalic portion of the subscapularis.

Associations with tenosynovitis, tendinosis and subluxation of the LHBT occur frequently and are an important cause of pain. In our study, the frequency of patients with biceps involvement was 61\% (95\% confidence interval: $38.6-83.6 \%$ ). Comparison of the interval in this study with results in the literature, which show involvement in 31 to $56 \%$ of the cases, indicates that our results were similar. However, the first interval presented greater amplitude because of the small number of samples ${ }^{(9,11,12)}$.

Bennett advocated repairing the subscapularis in association with reconstruction of the medial ligament complex of the LHBT, with the aim of recovering its stability in the intertubercular sulcus, given that repair of the subscapularis alone was insufficient to prevent its subluxation ${ }^{(18)}$. Burkhart and Tehrany ${ }^{(9)}$ recommended that tenotomy or tenodesis of the LHBT should always be done when it was found to be unstable during the arthroscopic procedure. These authors believed that the arthroscopic procedure for reconstructing the ligament complex was flawed and was responsible for compromising the fixation of the subscapularis. We agree with Burkhart, and we believe that situations in which the LHBT remains unstable or degenerated are an important reason for lack of success, because the painful condition is perpetuated. Provocative test results for the biceps (Speed and Yergason) are common findings in these patients ${ }^{(19,20)}$.

Despite reports in the literature that patients with subscapular tears present increased amplitude of passive external rotation, there was no statistical difference in our sample between the affected limb and the contralateral limb. This may be related to the percentage of the patients who undergo operations with deinsertions that are only partial. It is known that patients with partial ruptures may such increases that are less perceptible on clinical examination ${ }^{(18)}$. 
Subcoracoid impact has been suggested to be a possible cause of partial or total tearing of the subscapularis and the rotator cuff, as well as a factor triggering anterior pain in the shoulder. Some studies have suggested that the subscapular tendon is subjected to high tension on its posterior (convex) face when it crosses the stenosed subcoracoid space, thereby initially leading to rupture of the joint fibers (Figure 1). Such lesions have been named tensile undersurface fiber failure $(\mathrm{TUFF})^{(21,22)}$. The normal coracohumeral distance is 8.7 to $11 \mathrm{~mm}^{(23,24)}$. We do not believe that subcoracoid impact is the primary etiology of subscapular lesions. There are large divergences of opinion in the literature regarding whether this type of lesion exists. Because of the lack of scientific evidence, we did not go ahead with coracoplasty in any of our cases.

All of the patients in our series underwent arthroscopic inspection of the subacromial space in order to investigate any lesions associated with other tendons. The cases in which signs of impact and/or subacromial spurs were identified underwent acromioplasty. This procedure was performed on 10 patients $(56 \%$ of the cases) and there was no statistically significant difference in comparison with the group that did not undergo decompression.

Burkhart and Tehrany ${ }^{(9)}$ reported that $92 \%$ of the results from arthroscopic repair of subscapular lesions were excellent, among 25 shoulders in patients of mean age 61 years and mean follow-up of 10.7 months.

Bennett ${ }^{(18)}$ evaluated the results from eight patients with isolated tears of the subscapularis that were repaired arthroscopically, with a minimum follow-up of two years and a maximum of four years. They observed satisfactory results over both the short and the long term. Their surgical technique used not only the standard portals but also an accessory anterolateral portal and a portal through the supraspinatus in order to reconstruct the reflection pulley.

Kim et $a l^{(25)}$ evaluated 29 patients of mean age 54 years with isolated partial joint lesions of the subscapularis who underwent arthroscopic repair. The mean length of follow-up was 2.3 years, with 18 excellent results, 10 good results and one failure.

Edwards et $a l^{(26)}$ evaluated the results from arthroscopic debridement of isolated lesions of the subscapularis and tenotomy of the biceps in 11 patients with injuries that were considered to be arthroscopically irreparable or patients who did not choose to follow the entire rehabilitation protocol, if the lesion was repaired. These authors demonstrated good results and high satisfaction among the patients.

Lafosse et $a l^{(27)}$ published prospective results from 17 patients of mean age 47 years with isolated tears of the subscapularis who underwent arthroscopic repair. The mean follow-up was 2.4 years; 12 patients were very satisfied, four were satisfied and one was dissatisfied.

Adams et $a l^{(28)}$ assessed the medium-term results (three years of follow-up) from 40 patients with tears of the subscapularis. There were only seven patients with an isolated tear of the subscapularis. Coracoplasty was performed in $46 \%$ of the cases, and was indicated when the coracohumeral interval was less than $6 \mathrm{~mm}$. These authors reported that $80 \%$ of the results were excellent and good.

Balsini et $a l^{(29)}$ retrospectively evaluated the results from 12 patients who underwent arthroscopic repair of isolated complete lesions of the subscapular tendon. After a minimum follow-up of one year, there were satisfactory results in $91.67 \%$ of the cases. These authors performed coracoplasty in $33 \%$ of the cases, which was indicated when the coracohumeral space seen during arthroscopy was less than $6 \mathrm{~mm}$.

In our sample, occurrences of rerupture of the subscapularis were confirmed through magnetic resonance imaging in three cases. In clinical examinations on these patients, they presented positive tests for subscapular insufficiency (lift-off and belly-press). However, in assessing the Constant score, as validated by Boehm, we found that these patients presented adequate results.

In our sample, we observed that $83 \%$ of the results were good and excellent, while $17 \%$ were adequate. The LHBT was frequently affected $(61 \%$ of the cases), thus proving its close relationship with subscapular lesions.

\section{CONCLUSIONS}

There was no statistically significant difference in preoperative external rotation between the affected and contralateral sides $(\mathrm{p}=0.073)$;

There was no significant loss in external rotation after the operation $(\mathrm{p}=0.091)$; 
The LHBT may have a normal presentation in deinsertions of the subscapular tendon, provided that the reflection pulley is preserved;

The lesions of the LHBT did not influence the final result, according to the Constant and Murley index $(\mathrm{p}=0.083)$;

Acromioplasty did not have any statistical influence on the results $(\mathrm{p}=0.57)$;

The arthroscopic repair on the deinsertions of the subscapular tendon presented a high rate of favorable results $(83 \%$ of the results were excellent and good); and

The rerupture rate among the arthroscopic repairs on the subscapular tendon was $16.6 \%$.

\section{REFERENCES}

1. Keating JF, Waterworth $P$, Shaw-Dunn J, Crossan J. The relative strengths of the rotator cuff muscles. A cadaver study. J Bone Joint Surg Br. 1993;75(1):137-40.

2. Warner JJ. Management of massive irreparable rotator cuff tears: the role of tendon transfer. Instr Course Lect. 2001;50:63-71.

3. Hunt SA, Kwon YW, Zuckerman JD. The rotator interval: anatomy, pathology, and strategies for treatment. J Am Acad Orthop Surg. 2007;15(4):218-27.

4. Jost B, Koch PP, Gerber C. Anatomy and functional aspects of the rotator interval. J Shoulder Elbow Surg. 2000;9(4):336-41.

5. Gerber $\mathrm{C}$, Hersche $\mathrm{O}$. Tendon transfers for the treatment of irreparable rotator cuff defects. Orthop Clin North Am. 1997;28(2):195-203.

6. Arai R, Sugaya H, Mochizuki T, Nimura A, Moriishi J, Akita K. Subscapularis tendon tear: an anatomic and clinical investigation. Arthroscopy. 2008;24(9):997-1004.

7. Pearsall AWt, Holovacs TF, Speer KP. The intra-articular component of the subscapularis tendon: anatomic and histological correlation in reference to surgical release in patients with frozen-shoulder syndrome. Arthroscopy. 2000;16(3):236-42.

8. Lyons RP, Green A. Subscapularis tendon tears. J Am Acad Orthop Surg. 2005;13(5):353-63.

9. Burkhart SS, Tehrany AM. Arthroscopic subscapularis tendon repair: Technique and preliminary results. Arthroscopy. 2002;18(5):454-63.

10. Bennett WF. Arthroscopic repair of anterosuperior (supraspinatus/subscapularis) rotator cuff tears: a prospective cohort with 2- to 4-year follow-up. Classification of biceps subluxation/instability. Arthroscopy. 2003;19(1):21-33.

11. Gerber C, Krushell RJ. Isolated rupture of the tendon of the subscapularis muscle. Clinical features in 16 cases. J Bone Joint Surg Br. 1991;73(3):389-94.

12. Gerber $C$, Hersche $O$, Farron $A$. Isolated rupture of the subscapularis tendon. J Bone Joint Surg Am. 1996;78(7):1015-23.

13. Adams CR, Schoolfield JD, Burkhart SS. Accuracy of preoperative magnetic resonance imaging in predicting a subscapularis tendon tear based on arthroscopy. Arthroscopy. 2010;26(11):1427-33.

14. Constant CR, Murley AH. A clinical method of functional assessment of the shoulder. Clin Orthop Relat Res. 1987;(214):160-4.

15. Boehm D. Scores. In: Gohlke F, editor. Schulter: das Standardwerk für Klinik und Praxis. New York: Thieme; 2002. p. 98-104.
16. Wright JM, Heavrin B, Hawkins RJ, Noonan T. Arthroscopic visualization of the subscapularis tendon. Arthroscopy. 2001;17(7):677-84.

17. Burkhart SS, Brady PC. Arthroscopic subscapularis repair: surgical tips and pearls A to Z. Arthroscopy. 2006;22(9):1014-27.

18. Bennett WF. Arthroscopic repair of isolated subscapularis tears: A prospective cohort with 2- to 4-year follow-up. Arthroscopy. 2003;19(2):131-43.

19. Yoshikawa GI, Hori K, Kaneko H, Matsusue Y, Murakami M. Acute subscapularis tendon rupture caused by throwing: a case report. J Shoulder Elbow Surg. 2005;14(2):218-20.

20. Deutsch A, Altchek DW, Veltri DM, Potter HG, Warren RF. Traumatic tears of the subscapularis tendon. Clinical diagnosis, magnetic resonance imaging findings, and operative treatment. Am J Sports Med. 1997;25(1):13-22.

21. Richards DP, Burkhart SS, Campbell SE. Relation between narrowed coracohumeral distance and subscapularis tears. Arthroscopy. 2005;21(10):1223-8.

22. Lo IK, Burkhart SS. The etiology and assessment of subscapularis tendon tears: a case for subcoracoid impingement, the roller-wringer effect, and TUFF lesions of the subscapularis. Arthroscopy. 2003;19(10):1142-50.

23. Friedman RJ, Bonutti PM, Genez B. Cine magnetic resonance imaging of the subcoracoid region. Orthopedics. 1998;21(5):545-8.

24. Gerber C, Terrier F, Zehnder R, Ganz R. The subcoracoid space. An anatomic study. Clin Orthop Relat Res. 1987;(215):132-8.

25. Kim SH, Oh I, Park JS, Shin SK, Jeong WK. Intra-articular repair of an isolated partial articular-surface tear of the subscapularis tendon. Am J Sports Med. 2005;33(12):1825-30.

26. Edwards TB, Walch G, Nove-Josserand L, Boulahia A, Neyton L, O'Connor DP, et al. Arthroscopic debridement in the treatment of patients with isolated tears of the subscapularis. Arthroscopy. 2006;22(9):941-6.

27. Lafosse L, Jost B, Reiland Y, Audebert S, Toussaint B, Gobezie R. Structural integrity and clinical outcomes after arthroscopic repair of isolated subscapularis tears. J Bone Joint Surg Am. 2007;89(6):1184-93.

28. Adams CR, Schoolfield JD, Burkhart SS. The results of arthroscopic subscapularis tendon repairs. Arthroscopy. 2008;24(12):1381-9.

29. Balsini N, Balsini N, Kochen L, Palka L, Vilela A, Santos J. Reparo artroscópico das lesões completas isoladas do subescapular. Rev Bras Ortop. 2008;43(11/12):497-504. 